\title{
PEMANFAATAN LIMBAH KULIT KAYU AKASIA UNTUK PUPUK ORGANIK
}

\author{
Eldha Sampepana dan Ageng Priyatni
}

Balai Riset dan Standardisasi Industri Samarinda

\begin{abstract}
In modern agriculture, the use of organic fertilizer becomes more popular becouse it contains elements of natural nutrients such as N, P. K. Ca. Mg, which is needed by the soil for the growth of a plant. Organic fertilizers are derived from the waste of untapped Acacia bark. To take the advantage of Acacia mangium bark waste a study of organic fertilizer is carried out in order to find out the best composition of organic fertilizer from the waste. The result showed that the best composition of organic fertilizers bosed on elements of fertilizer treatment in the market is the treatment of acacia wood with bran and goat manure $\left(A_{3}\right)$.
\end{abstract}

Keywords : organic fertilizer, bark acacia

\section{PENDAHULUAN}

Saat ini, jumlah lahan pertanian yang produktif sudah semakin berkurang kesuburannya sehingga tanah menjadi marginal (miskin Hara). Hal ini diakibatkan menurunnya keseimbangan hara didalam tanah karena terjadi penipisan unsur mikro seperti $\mathrm{Zn}, \mathrm{Fe}, \mathrm{Cu}, \mathrm{Mn}$, dan Mo di dalam tanah yang sangat mempengaruhi aktivitas organisme tanah, serta menurunkan produktivitas pertanian dalam jangka panjang. Untuk mempertahankan kesuburan tanah, maka tanah tersebut scbaiknya diberikan suatu masukan atau input berupa pupuk organik. Pupuk organik dapat berperan sebagai pengikat butiran primer menjadi butir sekunder tanah dalam pembentukan agrcgat yang mantap. Keadaan ini besar pengaruhnya pada porositas. penyimpanan dan penyediaan air, acrasi tanah, dan suhu tanah. Pupuk organik merupakan pupuk yang sebagian besar atau seluruhnya terdiri atas bahan organik yang berasal dari tanaman dan atau hewan yang telah melalui proses penguraian atau dekomposisi yang dapat berbentuk padat atau cair yang digunakan mensuplai bahan organik untuk memperbaiki sifat fisik, kimia, dan biologi tanah. Pupuk organik memiliki fungsi kimia yang penting seperti: (I) penyediaan hara makro (N, $P$, $\mathrm{K}, \mathrm{Ca}, \mathrm{Mg}$, dan S) dan mikro seperti $\mathrm{Zn}, \mathrm{Cu}, \mathrm{Mo}$, Co, B. Mn, dan Fe, meskipun jumlahnya relatif sedikit. Penggunaan bahan organik dapat mencegah kurangnya unsur mikro pada tanah marginal atau tanah yang telah diusahakan secara intensif dengan pemupukan yang kurang seimbang; (2) meningkatkan kapasitas tukar kation (KTK) tanah; dan (3) dapat membentuk senyawa kompieks dengan ion logam yang meracuni tanaman seperti $\mathrm{Al}, \mathrm{Fe}$, dan $\mathrm{Mn}$, Balai Besar Litbang Sumberdaya Lahan Pertanian, 2006. Menurut Cristianoibey, (2010) bahwa pupuk organik dapat mengikat logam berat dan pencemar lainnya, mengurangi kemungkinannya tercuci dan terserap mahluk hidup, mendegradasi pencemar berbasis minyak bumi dalam tanah, memacu restorasi lahan basah (wetland) dengan menstimulasi karakter lahan basah, mengendalikan erosi, sebagai penyaring, mengurangi pencemar dalam air permukaan, memperbaiki struktur tanah, mengurangi berat volume tanah, meningkatkan permeabilitas (mengurangi potensi erosi). mengurangi pemadatan, meningkatkan kemampuan tanah menahan air Mengubah dan menstabilkan $\mathrm{pH}$. meningkatkan kapasitas pertukaran kation (memungkinkan tanah menahan nutrien lebih lama, mengurangi pencucian nutrien). menghidupi biota tanah hingga tanah lebih sehat dan menekan pertumbuhan penyakit tanaman.

Menurut McMeniman et al., (1986) bahwa pada kulit kayu akasia mengandung unsur-unsur $\mathrm{N}, \mathrm{P}, \mathrm{K}, \mathrm{Ca}, \mathrm{Mg}$. Unsur ini merupakan unsur penting didalam suatu pupuk yang sangat diperlukan oleh tanah untuk pertumbuhan suatı tanaman, dan unsur ini tidak meninggalkan residu pada tanaman sehingga aman bagi manusia.

Pupuk organik yang terbuat dari sisa mahluk hidup seperti tanaman, diantaranya 
limbah kulit kayu akasia mangium. Limbah kulit kayu akasia mangium yang diperoleh dari limbah yang dihasilkan oleh industri perkayuan terutama pada industri MDF yang menggunakan bahan baku akasia mangium. Salah satu industri MDF yang ada di Kalimantan Tiumur adalah PT. Sumalindo Lestari jaya. Berdasarkan data lapangan tahun 2008, industri ini akan menghasilkan limbah kulit kayu akasia mangium yaitu 1500 ton/ bulan yang selama ini belum termanfaatkan, sehingga menjadi suatu permasalahan bagi industri tersebut kususnya dalam hal pembuangan karena memerlukan suatu ruang/tempat yang luas.

Dengan berlimpahnya limbah kulit kayu akasia ini, maka dilakukan suatu penelitian tentang penelitian pemanfaatan limbah kulit kayu akasia untuk pupuk organik dengan tujuan untuk mengetahui komposisi campuran terbaik pupuk organik dari kulit kayu akasia mangium.

Pembuatan pupuk organik menurut Simamora, (2006) pada prinsipnya cukup mudah karena dapat dilakukan dengan cara membiarkan bahan organik (dedaunan, sisa pemanenen) hingga melapuk. Selain itu juga dengan menambahkan aktivator untuk mempercepat proses penguraian/dekomposisi. Sedangkan Suroto, (2005) menyatakan bahwa bahan yang digunakan dalam pupuk organik adalah tandan kosong sawit yang dicacah dengan ukuran $0,5 \mathrm{~cm}$ $\times 0,5 \mathrm{~cm}$ hinga serbuk, kemudian campurkan dengan limbah lumpur sekunder sawit, serbuk gergaji dan dedak secara perlahan-lahan sampai merata hingga

kandungan air 30-40\%, yang dapat dilihat dengan cara bahan yang telah dicampur dikepal, maka air yang ada dalam bahan campuran tidak menetes dan akan mekar bila kepalan dilepas. Bahan yang telah dicampur dimasukkan kedalam karung goni kemudian ujung permukaaan atas karung goni diikat dan ditutup dengan terpal. Suhu tumpukan dipertahankan antara $40-50^{\circ} \mathrm{C}$, untuk mengontrol suhunya setiap hari diukur. Apabila suhunya meningkat maka dilakukan pembalikan, biarkan sebentar kemudian tutup kembali hingga pupuk menjadi matang ( \pm 30 40 hari).

\section{BAHAN DAN METODE}

\section{Bahan dan Alat}

Bahan yang digunakan antara lain : kulit kayu akasia, EM4 (Effective Microorganisme 4 yang mengandung lactobocillus, actinomycetes, bakteri pelarut fosfat, yeast/ragi, bakteri fotosintetik). gula, dedak, kotoran hewan (kambing), kapur. karung plastik, kertas lakmus dan terpal. Sedangkan alat yang digunakan antar lain : skop, baskom, ember, panji, pengaduk, timbangan, termometer, parang, oven. AAS (Atomic Absorbtion Spektrofotometer), Spektrofotometer.

\section{Metode}

\section{Cara Pembuatan Pupuk Organik}

Proses Pembuatan pupuk organik dari limbah kulit kayu akasia yaitu limbah kulit kayu Akasia disortir terlebih dahulu kemudian dipotong-potong hingga menjadi ukuran $0,5 \times 0.5$ $\mathrm{cm}$, agar memudahkan dalam proses pembuatan serbuk. Disamping itu dedak. kotoran hewan (kambing), kapur, gula dan EM4 ditimbang sesuai dengan perlakuan pada Tabel 1.

Tabel 1. Komposisi Pembuatan Pupuk Organik dari Limbah Kulit Kayu Akasia

\begin{tabular}{ccccccc}
\hline Kode & $\begin{array}{c}\text { Kulit Kayu } \\
\text { Akasia }(\mathrm{g})\end{array}$ & $\begin{array}{c}\text { Dedak } \\
(\mathrm{g})\end{array}$ & $\begin{array}{c}\text { Kapur } \\
(\mathrm{g})\end{array}$ & $\begin{array}{c}\text { EM4 } \\
(\mathrm{ml})\end{array}$ & $\begin{array}{c}\text { Gula } \\
(\mathrm{g})\end{array}$ & $\begin{array}{c}\text { Kotoran } \\
\text { Kambing }(\mathrm{g})\end{array}$ \\
\hline $\mathrm{BLK}$ & 3000 & - & - & - & - & - \\
\hline $\mathrm{A}_{1}$ & 3000 & - & - & 3 & 12 & - \\
\hline $\mathrm{A}_{2}$ & 2700 & 300 & 0,5 & 3 & 12 & - \\
\hline $\mathrm{A}_{3}$ & 1700 & 300 & 0,5 & 3 & 12 & 1000 \\
\hline
\end{tabular}

Setelah menimbang masing-masing bahan pada tabel I, bahan tersebut dicampurkan sesuai dengan perlakuan tersebut, aduk secara perlahan-lahan sampai merata hingga kandungan 
air $30-40 \%$, yang dapat dilihat dengan cara bahan yang telah dicampur dikepal, maka air yang ada dalam bahan campuran tidak menetes dan akan mekar bila kepalan dilepas. Bahan yang telah dicampur dimasukkan kedalam kantong plastik sesuai dengan perlakuan dan ukur $\mathrm{pH}$, suhu bahan tersebut lalu disimpan didalam ruangan yang tidak kontak sinar matahari selama proses penguraian /dekomposisi. Selama proses penyimpanan pupuk diperlukan waktu I (satu) kali seminggu untuk membolak-balikkan bahan supaya udara banyak masuk kedalam celah-celah tumpukkan pupuk agar suhu pada saat penguraian/dekomposisi tidak tinggi dan proses penguraiaan/ dekomposisi merata. Waktu pematangan pupuk organik yang dibutuhkan selama proses penguraian/dekomposisi selama 6 (enam) minggu.
Parameter pengujian pupuk organik dari kombinasi limbah kulit kayu akasia yang dilakukan antara lain : Fosfat $(\mathrm{P})$, magnesium (Mg), Kalsium (Ca) mengacu pada SNI 02-3776-1995 tentang Pupuk Phosfat Alam, parameter $\mathrm{K}_{2} \mathrm{O}$ dan Nitrogen (N) mengacu pada SNI 02-2803-2000 tentang Pupuk NPK Padat, dan untuk pengukur $\mathrm{pH}$ menggunakan kertas lakmus. Sedangkan $\mathrm{C}$ Organik dan $\mathrm{C} / \mathrm{N}$ rasio dengan metode Walkley dan Black.

\section{HASIL DAN PEMBAHASAN}

Dari hasil penelitian yang telah diuji statistik dengan menggunakan nilai rata-rata (mean) dari hasil pengujian sampel yang dianalisa,menunjukkan bahwa kandungan unsur hara pada pupuk organik yang dihasilkan dapat dilihat pada Tabel 2.

\section{Pengujian}

Tabel 2. Hasil Penelitian Untuk Kandungan Unsur Hara Pupuk

\begin{tabular}{|c|c|c|c|c|c|}
\hline Parameter & BLK & $A_{1}$ & $A_{2}$ & $A_{3}$ & $\begin{array}{c}\text { Standar Pupuk } \\
\text { di Pasaran' }\end{array}$ \\
\hline C-Organik $(\%)$ & 32,47 & 37,85 & 26,04 & 31.77 & $4.83-8$ \\
\hline $\mathrm{P}_{2} \mathrm{O}_{5}(\%)$ & 0,15 & 0.22 & 0.29 & 0.81 & $0,35 \quad 1,12$ \\
\hline $\mathrm{K}_{2} \mathrm{O}(\%)$ & 0.18 & 0.36 & 0,38 & 1.75 & $0.32 \quad 0.80$ \\
\hline$N(\%)$ & 0.11 & 0.11 & 0.20 & 0.49 & $0.10 \quad 0.51$ \\
\hline $\mathrm{C} / \mathrm{N}$ rasio & 29,52 & 34.41 & 13.02 & 6,48 & $=$ \\
\hline$M g(\%)$ & 0,36 & 0.75 & 1.13 & 1.40 & $0.10 \quad 0.19$ \\
\hline $\mathrm{Ca}(\%)$ & 1,87 & 3.12 & 3.25 & 3,73 & $1.00 \quad 2,09$ \\
\hline $\mathrm{pH}$ & 7 & 7 & 7 & 7 & - \\
\hline $\begin{array}{l}\text { Kelembaban } \\
(\%)\end{array}$ & 66,67 & 66,49 & 68,40 & 70,99 & $41 \quad 43$ \\
\hline Suhu $\left({ }^{D} \mathrm{C}\right)$ & 29 & 29 & 29 & 29 & - \\
\hline Warna & $\begin{array}{c}\text { coklat } \\
\text { kehitaman }\end{array}$ & $\begin{array}{l}\text { agak hitam } \\
\text { kecoklatan }\end{array}$ & hitam kecoklatan & $\begin{array}{l}\text { agak coklat } \\
\text { kehitaman }\end{array}$ & - \\
\hline Waktu (minggu) & 6 & 6 & 6 & 6 & - \\
\hline Tekstur & belum remah & $\begin{array}{c}\text { agak kurang } \\
\text { remah }\end{array}$ & kurang remah & agak remah & - \\
\hline
\end{tabular}

Keterangan: 1) Musnamar Ismawati E., 2003; BLK : blangko; $A_{1}$ : Perlakuan kulit kayu Akasia dengan penambahan dedak dan tanpa kotoran kambing: $A_{2}$ : Perlakuan kulit kayu Akosia dengan dedak, kotoran kambing dan EM4 (Effective Microorganisme 4): $A_{j}$ : Perlakuan kulit kayu Akasia dengan EM4 (Effective Microorganisme 4)

\section{Penentuan Nilai C-Organik dan $\mathrm{C} / \mathrm{N}$ rasio}

Nilai $\mathrm{C} / \mathrm{N}$ rasio merupakan faktor penting yang mempengaruhi kinerja bakteri. Dari hasil penelitian diatas bahwa nilai rataan $C$ - organik tertinggi pada perlakuan kulit kayu Akasia dengan EM4 (Effective Microorganisme 4) $\left(\boldsymbol{A}_{l}\right)$ yaitu $37,85 \%$ dan terendah pada perlakuan kulit kayu

30 Eldha Sampepana, Ageng Priyatni

Pentanfaatan Limbah Kuin Kayu Akasia Untuk Pupuk Organik kambing $\left(A_{2}\right)$ yaitu $26,04 \%$. Sedangkan untuk nilai rataan $\mathrm{C} / \mathrm{N}$ rasio tertinggi pada perlakuan kulit kayu Akasia dengan EM4 (Effective Microorganisme 4$) /\left(A_{1}\right)$ yaitu $34,41 \%$ bila dibandingkan dengan nilai $\mathrm{C} / \mathrm{N}$ tanah menurut Indriani, (2004) dalam Suroto, (2005) adalah < $20 \%$, maka nilai $\mathrm{C} / \mathrm{N}$ pada perlakuan kulit kayu Akasia dengan EM4 (Effective Microorganisme 4)/ $\left(\mathbf{A}_{1}\right)$ dan blanko lebih besar dari $\mathrm{C} / \mathrm{N}$ tanah. $\mathrm{Hal}$ 
ini menunjukkan bahwa proses penguraian atau dekomposisi masih membutuhkan waktu yang lama sehingga mengakibatkan unsur $C$-organik yang berfungsi sebagai sumber energi bagi bakteri akan menghasilkan buangan berupa asam organik, alkohol, dan sebagainya akan membentuk karbondioksida $\left(\mathrm{CO}_{2}\right)$ dan gas metan $(\mathrm{CH} 4)$, Yuwono, 2005. Selain itu juga bahan yang digunakan dalam perlakuan masih mengandung selulosa, hemiselulosa, lignin tinggi sehingga mikroorganisme pada saat dekomposisi/penguraian tidak mampu mengurainya sehingga pupuk menjadi tidak remah/belum matang. Sedangkan menurut Musnamar Ismawati, (2003) bahwa pada proses aerob, C-organik yang dibebaskan dalam bentuk $\mathrm{CO}_{2}$ dan terjadinya oksidasi yang tidak sempurna, dan sebagian karbon digunakan untuk pembentukan sel-sel mikroba, sehingga jumlah $\mathrm{CO}_{2}$ yang dihasilkan tinggi dan $\mathrm{O}_{2}$ yang dikonsumsi tergantung tipe substrat, faktor lingkungan serta mikroba yang terlibat.

Untuk nilai rataan terendah pada perlakuan kulit kayu Akasia dengan dedak, kotoran kambing dan EM4 $\left(\mathbf{A}_{3}\right)$ yaitu $6,48 \%$ dan perlakuan kulit kayu Akasia dengan penambahan dedak, EM4 dan tanpa kotoran kambing/ $\left(\mathbf{A}_{2}\right)$ yaitu $13,02 \%$ bila dibandingkan dengan $\mathrm{C} / \mathrm{N}$ tanah lebih kecil. Hal ini menunjukkan bahwa bahan organik dalam perlakuan tersebut dapat terurai dengan baik karena proses metabolisme mikroorganisme lebih efesien dan oksidasi sempurna sehingga menghasilkan sedikit $\mathrm{CO} 2$. Selain itu juga pada perlakuan $\left(\mathbf{A}_{3}\right)$ mengalami penambahan kotoran kambing, dimana kotoran kambing banyak mengandung unsur nitrogen $(\mathrm{N})$, dimana unsur ini merupakan nutrisi bagi mikroorganisme sehingga mikroorganisme bekerja dengan baik dalam dalam proses penguraian/dekomposisi sehingga bahan organik dalam perlakuan tersebut dapat terurai.

\section{Penentuan Walktu Penguraian /Dekomposisi Pupuk}

Waktu yang ditempuh dalam dalam proses penguraian pupuk hingga menjadi matang yaitu selama 6 (enam) minggu, bila dibandingkan waktu penguraian atau dekomposisi menurut Musnamar Ismawati, (2003) adalah 14 hari. Hal ini disebabkan oleh bahan yang digunakan yaitu kulit kayu akasia yang terdiri dari cork combium dan cork yang banyak mengandung selulosa, hemiselulosa dan lignin schingga mikroorganisme dalam proses penguraian atau dekomposisi membutuhkan waktu yang lama dalam penguraiannya. Selain itu juga penambahan EM4 sedikit, penambahan mikroorganisme khusus penghancur selulosa, hemiselulosa dan lignin dalam EM4 tidak ada, serta tingginya kadar air yang digunakan mengakibatkan mengurangi ketersediaan oksigen, membentuk zona anaerob, memperlambat proses pengomposan, dan terbentuk bau busuk. Hal ini dipertegas oleh Cristianoibey, 2010 bahwa bahan kompos yang mengandung bahan sulit terdekomposisi seperti lignin dan selulosa membutuhkan waktu pengomposan lebih lama, dan dekomposisi lignin selulosa terjadi lebih cepat pada fase pendinginan.

Penyimpanan yang terlalu tebal menimbulkan suhu yang tinggi sehingga mikroorganisme dalam proses dekomposisi pupuk tidak bekerja maksimal atau mati, dan dan ukuran bahan yang digunakan tidak serbuk sehingga sentuhan mikroorganisme pada bahan tidak luas sehingga membutuhkan waktu dekomposisi terlalu lama. Menurut Soeyanto, (1982) bahwa dalam pembuatan pupuk banyak faktor-faktor mempengaruhi perombakan atau penguraian pupuk antara lain udara, suhu, kelembaban, EM4, jenis bahan yang digunakan, ukuran bahan, waktu dekomposisi, cara pengomposan, cara penyimpanan. Sedangkan menurut Suriawiria, Unus, (2002) bahwa semakin kecil dan homogen bentuk bahan semakin cepat dan baik pula proses pengomposan.

Indriani, 2004 dalam Suroto, (2005) menyatakan bahwa ukuran bahan yang tidak keras dicacah dengan ukuran yang agak besar sekitar $5 \mathrm{~cm}$ sedangkan bahan yang keras sebaiknya dicacah hingga $0,5 \mathrm{~cm}-4 \mathrm{~cm}$ hingga serbuk agar proses penguraian/ dekomposisi lebih cepat karena semakin luas permukaan makin banyak tersentuh oleh bakteri, serta membolak-balikkan pupuk bertujuan agar udara banyak masuk kedalam celah tumpukan pupuk sehingga makin cepat terjadinya pembusukkan artinya memperpendek lamanya proses penguraian pupuk. Begitu juga dengan penambahan EM4 (Effective Microorganisme 4), Semakin banyak digunakan dalam proses 
penguraian atau dekomposisi semakin cepat proses penguraian pembuatan pupuk, Soeyanto, 1982.

\section{Penentuan Nilai Unsur Nitrogen $(\mathrm{N})$ dan Unsur Kalium Sebagai $\mathrm{K}_{2} \mathrm{O}$}

Untuk unsur Nitrogen (N) nilai rataan tertinggi pada perlakuan kulit kayu Akasia dengan dedak dan kotoran kambing $\left(A_{3}\right)$ yaitu $0,49 \%$ dan terendah pada perlakuan blangko (BLK) dan perlakuan kulit kayu Akasia dengan EM4 (Effective Mieroorganisme 4)/ $\left(A_{2}\right)$ yaitu $0,11 \%$. Sedangkan unsur Kalium $\left(\mathrm{K}_{2} \mathrm{O}\right)$ nilai rataan tertinggi pada perlakuan kulit kayu Akasia dengan dedak dan kotoran kambing $\left(\mathrm{A}_{1}\right)$ yaitu $1,75 \%$ dan terendah pada perlakuan blangko (BLK) yaitu $0,18 \%$. Hal ini menunjukkan bahwa pada perlakuan $\left(\mathrm{A}_{2}\right)$ karena adanya penambahan dedak dan kotoran kambing. Menurut oleh Musnamar Ismawati, (2003) bahwa kotoran hewan banyak mengandung unsur makro seperti nitrogen $(\mathrm{N})$. fosfor (P). kalium (K), unsur mikro seperti kalsium (Ca), magnesium ( $\mathrm{Mg}$ ) dan sulfur (S). Sedangkan persentase kandungan hara pupuk pada kotoran kambing Menurut Musnamar Ismawati, (2003) adalah $N$ sebesar 0,83\% $0,95 \%$ dan $\mathrm{K}_{2} \mathrm{O}$ sebesar $1,00 \%-1,20 \%$.

Menurut Musnamar Ismawati, (2003) bahwa kandungan unsur hara dalam pupuk dapat hilang karena beberapa sebab diantaranya penguapan, penyerapan, dekomposisi dan penyimpanan. Proses penguapan dan penyerapan dapat menyebabkan kehilangan kandungan unsur hara dalam pupuk yaitu unsur nitrogen $(N)$ sebesar $50 \%$ dan Kalium (K) sebesar $60 \%$. Sedangkan kehilangan unsur hara selama proses penguraian atau dekomposisi yaitu unsur nitrogen (N). Pada proses dekomposisi yang digunakan adalah proses aerob karena menggunakan mikroorganisme yaitu EM4 (Effective Microorganisme 4). Proses aerob terjadi sangat cepat, menghasilkan panas yang tinggi, sehingga terjadi kehilangan nitrogen $(N)$ karena menguap membentuk amonium dan nitrat. Selain itu juga terbentuk humus dan senyawa-senyawa teroksidasi seperti $\mathrm{NO}_{3} ; \mathrm{SO}_{4}^{-}$dan $\mathrm{CO}_{2}$, dan proses penyimpanan sangat berpengaruh kehilangan unsur hara dalam pupuk yang dihasilkan karena disimpan dalam tempat yang tertutup rapat dan tebal sehingga menimbulkan suhu penyimpanan menjadi panas, sehingga unsur hara menguap dan berkurang, serta tingginya kadar air yang digunakan mengakibatkan nutrient seperti nitrogen dalam pupuk terlarut, Cristianoibey, 2010.

Penentuan Nilai Unsur Hara Fosfor sebagai $\mathrm{P}_{2} \mathrm{O}_{5}$, Kalsium (Ca) dan Magnesium ( $\mathrm{Mg}$ )

Untuk unsur fosior sebagai $\mathrm{P}_{2} \mathrm{O}_{5}$, nilai rataan tertinggi pada perlakuan kulit kayu Akasia dengan dedak dan kotoran kambing $\left(\mathbf{A}_{\mathrm{j}}\right)$ yaitu $0,81 \%$ dan terendah pada blangko (BLK) yaitu $0,15 \%$, dan untuk unsur kalsium (Ca) nilai rataan tertinggi pada perlakuan kulit kayu Akasia dengan dedak dan kotoran kambing $\left(A_{3}\right)$ yaitu $3,73 \%$ dan terendah pada blangko (BLK) yaitu $1,87 \%$. Sedangkan untuk unsur magnesium (Mg) nilai rataan tertinggi pada perlakuan kulit kayu Akasia dengan dedak dan kotoran kambing $\left(A_{3}\right)$ yaitu $1.40 \%$ dan terendah pada blangko (BLK) yaitu $0,36 \%$. Hal ini menunjukan bahwa pada perlakuan kulit kayu Akasia dengan dedak dan kotoran kambing $\left(\mathbf{A}_{3}\right)$ mengalami penambahan kotoran hewan yaitu kotoran kambing. Menurut Musnamar Ismawati, (2003) bahwa persentase kandungan fosfor $(\mathrm{P})$ pada kotoran kambing sebesar $0.35 \%-0,51 \%$.

Unsur fosfor (P) akan berkurang discbabkan bahan yang digunakan yaitu kulit kayu akasia mempunyai $\mathrm{pH}$ asam serta kadar airnya tinggi mengakibatkan mikroorganisme yang fungsinya untuk mengurai tidak maksimal sehingga terbentuknya humus pada pupuk berkurang atau teksturnya kurang remah. Hal ini mengakibatkan unsur-unsur dalam pupuk organik dari limbah kulit kayu Akasia belum terurai semua sehingga unsur-unsur dalam pupuk berkurang. Sclain itu juga unsur logam seperti kalsium (Ca) dan magnesium tinggi sehingga sehingga fosfor yang dihasilkan kecil atau berkurang. $\mathrm{Hal}$ ini ditegaskan oleh Musnamar Isnawati, (2003) bahwa fosfor organik terdapat dalam humus dan bahan organik. Unsur fosfor (P) sangat dipengaruhi oleh $\mathrm{pH}$. Pada $\mathrm{pH}$ rendah (asam) fosfor $(\mathrm{P})$ akan terikat oleh alumunium (Al) dan besi ( $\mathrm{Fe}$ ). Sementara $\mathrm{pH}$ tinggi (diatas 7 ), kalsium (Ca) dan magnesium ( $\mathrm{Mg}$ ) akan mengikat fosfor (P). Menurut Darmono (1995) dalam Hartanto Sapto Eddy, 2009 bahwa adanya toksisitas Al akan menyebabkan penurunan mineral dalam bahan organik tanah khususnya daya absorpsi 
terhadap unsur $\mathrm{P}$ dan akan menaikkan kandungan Ca dan Mg.

\section{KESIMPULAN}

Dari hasil penelitian dapat disimpulkan bahwa limbah kulit kayu akasia mangium dapat dimanfaatkan sebagai bahan baku pembuatan pupuk organik dengan komposisi campuran kulit kayu akasia dengan dedak, kotoran kambing dan EM4 (Effective Microorganisme 4)/ $\left(\mathbf{A}_{2}\right)$ dengan nilai unsur $N$ sebesar $0,49 \%$, nilai unsur $P$ sebesar $0,81 \%$, nilai unsur $\mathrm{K}$ sebesar $1,75 \%$, nilai unsur $\mathrm{Mg}$ sebesar $1,40 \%$, nilai unsur Ca sebesar $3,73 \%$ dan $\mathrm{C} / \mathrm{N}$ rasio sebesar $6,48 \%$.

\section{Ucapan Terima Kasih}

Pada kesempatan ini, kami mengucapkan terima kasih kepada Bapak Kepala Balai dalam penyediaan dana untuk penelitian ini. Paluphy Eka Yustini, Zainuddin Masfut serta semua pihak yang telah membantu pelaksanaan penelitian baik dalam perlakuan, menganalisa hingga tersusunnya laporan ini.

\section{DAFTAR PUSTAKA}

Balai Besar Litbang Sumberdaya Lahan Pertanian, 2006. Pupuk Organik dan Pupuk Hayati.

http://balittanah,litbang.deptan.go.id/dok umentasi/juknis/pupuk\%20organik.pdf. Tanggal 22 Maret 2010

Cristianoibey, 2010. Bioteknologi Dekomposisi Bahan Organik. Tanggal 10 Juni 2010

Hartanto Sapto Eddy, 2009. Peneropan SNI Produk Pupuk Fosfot Alam Untuk Pertanian Oleh Industri. Balai Besar Industri Agro. Bogor. www.bsn.go.id/files/348256349/Litbang $\% 202009 /$ Bab\%207.pdf. Tanggal 22 Maret 2010
MeMeniman, 1986. The nutritional evaluation of south-west Queensland pasture. II. The intake and digestion of organik matter and nitrogen by sheep grazing on mitchell grass and mulga/grassland association.

Australian Journal of Agricultural Research 37: $303-314$.

Musnamar Ismawati E, 2003. Pupuk Organik Padot (Pembuatan dan Aplikosinya). Penebar Swadaya Bogor.

Parnata, 2004. Pupuk organik cair (aplikasi dan Manfaatnyo). Agromedia pustaka. Bandung

Simamora, 2006. Meningkatkan Kualitas Pupuk. Agro Media Pustaka. Jakarta.

SNI 02-3776-1995. Pupuk Phosfat Alom. Badan Standardisasi Industri Nasional.

SNI 02-2803-2000. Pupuk NPK Podat.Badan Standardisasi Industri Nasional.

Soeyanto ,T. 1982."Cara Membuat Sampah jadi Arong don Kompos", Yudhistira, Jakarta

Sulistyawati E. Nugraha R. Efektivitas Kompos Sampah Perkataan Sebagai Pupuk Organik Dalam meningkatkan Produktivitas Dan Menurunkan Biaya Produksi Budidaya Padi. Sekolah Ilmu dan Teknologi Hayati Institut Teknologi Bandung

Suriawiria Unus, 2002. Pupuk Organik Kompos Dari Sampah Bioteknologi Agroindustri, Humaniora Utama Press. Bandung

Suroto, HS. 2005. Pemanfaatan Tandan Kosong Sawit Sebagai Pupuk Bokasi. Buletin Bimada No. 19 Volume 13 Juni Tahun 2005 . Balai Riset dan Standardisasi Industri Samarinda

Sutiyoso, Yos. 2003. Merumu Pupuk Hidroponik: Tanaman Buah, Tanaman Sayur, Tanaman Hias. Penebar Swadaya. jakarta

Yuwono D., 2007 . Pupuk. Penebar swadaya. Jakarta 